\title{
Rousseau e suas autobiografias: além do autorretrato
}

\author{
Rousseau and his autobiographies: beyond self-portrait
}

\author{
Adriano Eurípedes Medeiros Martins \\ adrianomartins@iftm.edu.br \\ (Instituto Federal do Triângulo Mineiro, Minas Gerais, Brasil)
}

\begin{abstract}
Resumo: 0 sujeito que escreve sobre si mesmo e sua obra: eis a essência de uma obra autobiográfica. 0 estudo inicia pela abordagem da relação público-autor. Aqui os elementos "para quem" e "para quê", apesar de significativos, serão secundários em face do autor que as escreve. Defendemos que o autor é uno com sua obra. Assim, Rousseau, ao se defender nas Confissões (1764-1770), está defendendo, por exemplo, o Contrato Social. Tal situação se repetirá com outras quatro obras confessionais e autobiográficas: Cartas ao Sr. Malesherbes (1762), Profissão de Fé do Vigário Saboiano (1762), Diálogos de Rousseau Juiz de Jean-Jacques (1772) e Devaneios de um caminhante solitário (177678).
\end{abstract}

Palavras-chave: Rousseau; autobiografia; natureza humana.

\begin{abstract}
The subject who writes about himself and his work: that is the essence of an autobiographical work. The study begins with the approach to the publicauthor relationship. Here the elements "to whom"' and "what for", although significant, will be secondary in the face of the author that writes. We argue that the author is one with his work. Thus, when Rousseau defends himself in the Confessions (1764-1770), he is advocating, for example, for the Social Contract. This situation is repeated in four other confessional and autobiographical works: Letters to Mr. Malesherbes (1762), Profession of Faith of the Savoyard Vicar (1762), Dialogues: Rousseau Judge JeanJacques (1772) and Reveries of a Solitary Walker (1776-78).
\end{abstract}

Keywords: Rousseau; autobiography; human nature.

DOI: http://dx.doi.org/10.11606/issn.2318-9800.v22i3p51-56

O sujeito que escreve sobre si mesmo e sua obra: eis a essência de uma obra autobiográfica. Entretanto, no caso Rousseau, ela não tem por finalidade ser uma obra na qual o sujeito-autor seja o objeto-fim do que é escrito. E é a partir desta afirmação que propomos abordar uma temática específica: o que motiva o nosso autor a optar por obras autobiográficas e não por aqueles textos "diretos", com temáticas mais específicas?

O Genebrino, sujeito-objeto do texto autobiográfico, alerta-nos num de seus Devaneios: “consagro meus dias a estudar-me a mim mesmo e a preparar de antemão as contas que não tardarei a dar a mim mesmo. Entreguemo-nos inteiramente à doçura de conversar com minha alma, já que é a única coisa que os homens não me 
podem tirar" (Rousseau, 1986, p.26). Não estamos diante de um mero desabafo; é a necessidade humana e existencial pela solidão. Mas, para quê? Para criar, é a sua solidão criadora. Trata-se de uma maneira inovadora de defender o homem e sua obra constantemente atacadas. Tais textos, escritos num intervalo de uns 15 anos (1762-1778), não são apenas solilóquios. Apesar de não ser visível num relance inicial, o outro - a alteridade -, não será um mero coadjuvante nestes textos. Ele vai falar de si para outrem. O que ele quer falar? "Só uma coisa tenho a temer nessa empreitada: não é dizer demais ou dizer mentiras, mas não dizer tudo ou calar mentiras" (Rousseau, 2008, p.176). Ou "o verdadeiro objetivo das minhas Confissões é fazer conhecer exatamente o meu íntimo" (idem, p.260). É, em síntese, um exporse, com fins de correção.

Correção não de si, mas do modo como é visto pelos seus contemporâneos. Por isto, estamos em face de um desvelar - seja a si mesmo, seja outrem, e não propriamente uma apologia. Daí seu fim corretivo - "esses homens de letras que, conferindo tudo à reputação, julgam meus sentimentos pelos seus” (Rousseau, 2009, p.18). Tal situação nos mostra um indivíduo preocupado com a maneira distorcida como poderá ser visto. Os infortúnios do dia-a-dia existem, mas são passageiros. Uma memória contaminada pode não ser reabilitada. Daí ele não aceitar ser parcialmente conhecido (cf. idem, p.25). Há algo de um autorresgate da memória de um vivo; ele quer outro veredicto das gerações futuras: "a posteridade 1 é sempre justa” (idem, p. 52).

José Saramago - o ensaísta português numa entrevista dada ao Jornal do Brasil em 2002 - afirmou que os livros deveriam trazer uma faixa em que viesse expresso: “Atenção, este livro leva uma pessoa dentro". As obras autobiográficas deixam isto evidente. Ocorre que no caso rousseauniano certa autobiografia visa defender outro texto que esteja sob "ataque” de seus ilustres contemporâneos. A título de ilustração, Rousseau, ao se defender nas Confissões (1764-1770), está também defendendo, por exemplo, o Contrato Social (1762). Tal situação se repetirá com as outras quatro obras confessionais e autobiográficas: Cartas ao Sr. Malesherbes (1762), Profissão de Fé do Vigário Saboiano (1762), Diálogos de Rousseau Juiz de Jean-Jacques (1772) e Devaneios de um caminhante solitário (1776-78).

Rousseau, um espírito itinerante, sabe que acumulou desafetos ao longo de vida e de sua carreira (cf. Rousseau, 2008, p.95). Talvez isto seja o início de uma explicação para a profícua produção de textos autobiográficos ao longo de uma década e meia. É o texto da resistência, da justiça e da verdade. Ao resistir, ele não resiste em apontar para os que fracassaram: "Temos aqui uma crítica séria contra 'homens que desejam brilhar e não convencer' e que o talento de Rousseau sabe

1 "Destinado a ser nesta vida a presa do erro e da mentira, espero a hora de minha libertação e o triunfo da verdade sem mais procura-la entre os mortais" (Rousseau, 2009, p.158). 
apresentar como uma verdade de todos os tempos" (Rousseau, 2009, p.8). Não por acaso, a clareza do sobrescrito aos Diálogos de Rousseau Juiz de Jean-Jacques: "a todo Francês que ama ainda a justiça e a verdade" (idem, p.153). É a confluência do verdadeiro e do justo. Como veremos, tais elementos estruturam sua análise do homem natural e do estado de natureza.

Em muitos casos, a crítica que the era endereçada visava muito mais a sua pessoa do que uma provável e plausível inconsistência de seus muitos escritos. Os textos autobiográficos são consistentes com um projeto de sua obra como um todo. Eis, então, que os temas confluem ou afluem para um mesmo lugar: refletir sobre o homem implica numa reflexão sobre o seu estado natural e as razões de sua corrupção e desigualdade. Entendemos que esta é uma linha argumentativa típica dos estudos filosóficos. E assim o será, também, nas obras autobiográficas. Diante desta nossa opção por tais textos, já antevemos uma crítica certa: alguns destes escritos rousseaunianos não poderiam ser encarados como autobiográficos.

Tomemos como referência o texto Confissões. Apenas recentemente as Confissões foram reconhecidas como obra que tem valor filosófico próprio e não um mero arejamento de uma alma inquieta. Tal reconhecimento, contudo, necessitou tomar um novo caminho e que implicou na aplicação de instrumentos e arcabouços conceituais oriundos dos estudos literários para melhor dimensionar o gênero autobiografia. Buscamos, por exemplo, em Philippe Lejeune o entendimento desta nova perspectiva, para quem a autobiografia deveria ser analisada como uma "narrativa [récit] retrospectiva em prosa que uma pessoa real faz de sua própria existência enfatizando sua vida individual, em particular, a história de sua personalidade" (Lejeune, 1975, p.14). É o uso da palavra numa estrutura ou forma narrativa eivada de elementos e análises típicas das ciências filosóficas. E, destacamos isto, na autobiografia frequentemente teremos que transcender a forma à procura de seus conteúdos que teimam em se esconderem de nós, os leitores. É uma obra que se sabe filha do seu tempo, mas que não se limita a uma dada época.

Por outro lado, na contramão da tentativa de valorização filosófica das obras autobiográficas, encontramos alguns elementos diversos nas teses de Paul De Man. Apoiado em alguns conceitos do Livro IX da Poética de Aristóteles, De Man recusa a qualificação de gênero literário às obras autobiográficas. Para ele, não deve se equiparar à dignidade de um gênero literário uma forma que transparece ser pouco respeitável e colossalmente autoindulgente, e cuja tentativa de definição, ainda que com ares de seriedade, "naufraga em questões que são ao mesmo tempo despropositadas e irrespondíveis" (De Man, 1989, p.68). Nesse quadro, algumas objeções merecem nossa reflexão: I) dificuldade em delimitar a fronteira entre autobiografia e ficção; II) diferenciar entre o trabalho dos autobiógrafos e dos romancistas. 
Podem alegar contra estas nossas proposições que estamos tornando muito elástico o conceito de autobiografia com vistas a forçar sua inserção no domínio da filosofia propriamente dita. Steltzig reconhece as dificuldades gerais daquela demarcação e sugere que ao menos uma parte do gênero pode ser tipificado de maneira mais fértil, a qual denomina de "autobiografia romântica". A autobiografia romântica pode ser caracterizada como:

um tipo de narrativa confessional do eu no final do século XVIII e início do XIX que como uma conta retrospectiva e a interpretação de como se formaram a identidade e a personalidade do escritor, artisticamente mescla realidade e imaginação, a historiográfica e os polos poéticos da narrativa - ou o que Goethe chama de "poesia" e a "verdade" de uma vida (Steltzig, 2000, p.8).

Deste modo, para Steltzig destacam-se positivamente na autobiografia romântica as distintas formas imaginativas que autores como Rousseau e Goethe deram à narrativa de suas próprias vidas. É Delfos encontrando-se com a história: o homem conhece a si mesmo na medida em que se aprofunda na compreensão dos diversos eventos da sua vida: "ninguém no mundo me conhece a não ser eu mesmo" (Rousseau, 2009, p.23). Eventos diversos tratados com sensibilidade e transparência nos textos autobiográficos que tratam da vida, obra e época do nosso Genebrino. Não negamos que trata-se de uma realidade mesclada com a imaginação: basta lembrarmos a importância de certa caminhada até Vincennes.

Convém esclarecermos que tanto as Confissões como as demais obras elencadas como autobiográficas misturam momentos de narrativa factual com outros ficcionais e poéticos. Nas Confissões essa dimensão “literário-poética” prolifera: o culto da natureza pura e originária, o rechaço ao artificialismo e às convenções da sociedade civil, a valorização intensa da experiência interior e subjetiva, o primado da expressão autêntica e espontânea que se oporá ao inautêntico e artificial do século das luzes, a busca por suas raízes pessoal e social, além da caracterização do progresso das ciências e das artes como um processo de alienação e desumanização da natureza humana originária. Ora, pelos assuntos até parece que estamos tratando de seus discursos político-moral-sociais ou do Contrato Social. De qualquer modo, reforçamos que isto serve para corroborar nossa de tese de intercomunicação entre seus textos.

Ressalvamos que este cenário de valorização e busca do homem interior não é o reino da pura translucidez. Aí, mesmo que sem ainda adentrarmos aos conteúdos das obras, analisando apenas os seus títulos, constatamos uma busca de distanciar-se de si mesmo e da sociedade, de utilizar-se de uma máscara. É um cenário psicoliterário complexo, pois se trata de uma máscara que visa transparecer melhor sua própria natureza humana, ela não está nos seus textos como uma barreira para que possa 
ocultar-se - seja de si mesmo, seja dos olhares dos seus leitores. É a paradoxal máscara do desvelamento e daí começamos a compreender sua opção por escrever: "a escolha que fiz de escrever e me esconder é precisamente a que me convém" (Rousseau, 2008, p.126). Se se quisesse esconder atrás de uma máscara qualquer, não nos teria legado qualquer obra, menos ainda aquelas consideradas autobiográficas.

É justamente diante deste complexo sujeito que nos deparamos, por exemplo, com outra obra intrincada: Os Devaneios do caminhante solitário. É o último texto escrito dos considerados autobiográficos. Neste livro, há uma maior nebulosidade a respeito de "para quem" se escreve, posto que não se trata de uma autobiografia típica em que se registram ações conexas a anos consecutivos. É como se a vida não fosse uma sequência temporal linear, mas repleta de devaneios, fragmentos de lembranças, "sonhos" que embaralham o passado, presente e futuro. É uma espécie de um tudo aqui e agora - totum simul. Até por isso poderia ser questionado o seu papel neste rol das autobiografias. Não deveríamos encaixotá-lo no mundo das ficções? Sustentamos o seu caráter autobiográfico na medida em que estamos diante de um sujeito que busca com paciência, zelo e afinco fazer aquilo que criticava no homem social: usar suas forças psíquicas para voltar-se a si mesmo e submeter-se a uma rigorosa autoavaliação de suas condutas, valores e o meio social no qual se inseriu ao longo da vida.

Considerando todo o panorama exposto acima, podemos delinear alguns modos mais específicos de tratarmos e lermos tais obras rousseaunianas. 0 preceito délfico "conhece-te a ti mesmo" tem muito a nos dizer do seu pensamento. O conhecimento de si para ele não é um problema, é um dado, o qual corrobora sua assertiva com as palavras de Jean-Jacques em Confissões: "Passando minha vida comigo, devo conhecer-me" (apud Starobinski, 1971, p.187). Assim, nota-se a incessante busca pelo autoconhecimento evidenciada no complexo Devaneios. Jean-Jacques mergulha em seu delírio e perde seus vínculos com os homens: "sei bem que o leitor não tem grande necessidade de saber tudo isso; eu é que tenho de o dizer" (Rousseau, 2008, p.43). Como já o demonstra a primeira frase da obra, "Eis-me, portanto, sozinho na terra, tendo apenas a mim mesmo como irmão, próximo, amigo, companhia" (Rousseau, 1986, p.23), que aparentemente restringe sua escrita para si, e que, igualmente, tem a si mesmo como irmão, amigo, companhia, enfatizando sua solidão (ou autossuficiência) em detrimento dos outros. Ainda assim, vale ressaltar que estar só não é o problema, ser condenado à solidão pelos seus pares e pela sociedade é que não se the parece justo e adequado. Por isso que muitas de suas obras parecem tratar de si, mas o alvo pode bem ser a sociedade e seus males.

A cisão entre ser sujeito e objeto incita a questão da fidelidade do retrato pintado por Rousseau, tal como o evidenciamos no prefácio das Confissões. Como é possível pintar-se exatamente ao natural, se o que se pinta já não é natural, 
encontra-se mediado pela escrita, e que se modificou quando em contato com o outro e consigo próprio? Rousseau pintou-se, mas também pintou os outros, os quais, por sua vez, o pintaram novamente. Como retrato final pode-se delinear um rosto inacabado, tal qual sua última caminhada da sua última obra autobiográfica, em que o ato de sentimento que funda o conhecimento de si não tem jamais o mesmo conteúdo e é indefinidamente renovável, como ocorre em um autorretrato.

\section{Referências}

De Man, P. (1989). “Autobiography as De-Facement”. In: The Retoric of Romanticism. Nova York: Columbia University Press.

Lejeune, P. (1975). Le Pacte autobiographique. Paris: Seuil.

Rousseau, J-J. (1959-1995). Oeuvres Complètes. Bernard Gagnebin e Marcel Raymond (orgs). Paris: Pléiade-Gallimard, 5 vol.

- (1971). Oeuvres Complètes. Jean Fabre e Michel Launay (orgs). Paris: L'Intégrale-Du Seuil, 3 vol.

- (1986). Os devaneios do caminhante solitário. Brasília: Editora Universidade de Brasília.

. (1999). Emílio ou da Educação. São Paulo: Martins Fontes.

- (2005). Carta a Christophe de Beaumont e outros escritos sobre a religião e a moral. Organização e apresentação de José Oscar de Almeida Marques. São Paulo: Estação Liberdade.

. (2008). Confissões. Bauru, SP: EDIPRO.

(2009). Textos autobiográficos \& outros escritos. São Paulo: Editora

UNESP.

Starobinski, J. (1971). Jean-Jacques Rousseau: la transparance de l'obstacle. Paris: Gallimard.

Stelzig, E. (2000). The Romantic Subject in Autobiography: Rousseau and Goethe. Charlottesville: Virginia University Press. 